\title{
Empowering people
}

\section{Open Education and Open Source for Sustainable Economic Activity}

\author{
Open education and open-source are essential \\ foundations for enabling civic engagement with \\ technologies and sustainable use. Makerspaces \\ can lead the way for structural change through \\ local learning and economic development. \\ By Maximilian Voigt
}

$\mathbf{R}$ esource-efficient living requires changes on numerous levels. These changes include, in particular, the use of technology, which is decisively shaped by individual skills, political framework conditions and the availability of open technologies and infrastructures. This is shown by juxtaposing the sustainability mantra of "reduce, reuse, recycle" with excerpts from the definition of "Open": "Open means anyone can freely access, use, modify, and share for any purpose." Without technicaltechnological competences, which at their core includes practical skills and systemic understanding that go beyond the application level, without open technologies such as open-source software and hardware, and without makerspaces that enable repair and self-learning by the general public, technology is always just a fast-moving consumer object that is difficult to adapt to new circumstances and to integrate into sustainable local cycles.

\section{A need for open technology teaching}

At the same time, competence development is not about disseminating in-depth engineering or IT skills more broadly. Rather, it is about understanding functional relationships that allow the assessment of technology, which is transferable to different concrete contexts. It is about basic craftsmanship, on a physical and digital level. And it is about the understanding and critical reflection of systemic contexts and political dimensions.

Current developments in education are at risk of falling short of these goals. Technology is equated with digital tools and skills that are largely limited to application. Skills that go beyond this are rarely in focus. What is therefore needed is teaching technologies openly, meaning methods that place the technical function at the centre and promote a self-determined approach to technology. Using a vacuum cleaner as an example, it is a matter of opening the plastic housing and understanding the mechanism behind it. Because only on this basis we can really make sustainable consumption decisions and repair to a certain degree by ourselves.

This is also about power. After all, in a society that is thoroughly permeated by technology, those who possess the knowledge of technologies can influence processes. This is not only evident in debates around the "Netzwerkdurchsetzungsgesetz" [Network Enforcement Act] or data retention, where an understanding of the subject matter is necessary to be able to evaluate arguments. It is also about framework conditions for the development of technology, for example with regard to the right to repair. This is where fundamental decisions on the repairability of objects are made. Should members of the public be able to obtain spare parts themselves, or only authorised dealers? Do spare parts have to be kept in stock at all? And should manufacturers design their equipment so that it is easy to repair? A broad response to these questions requires a basic understanding and awareness of technical issues.

\section{Taking open-source into the mainstream}

In addition to these individual competences, open technologies are also required. Thus, open technology development and repair is only feasible when the documentation of technical objects and software solutions are made available. This includes an open and modifiable design of technical devices. This also applies in particular to the sustainable development of technology. Open-source software and hardware solutions make it possible to re-use resources that have already been used, by collectively developing existing technology and improving faulty designs. A free licence ensures decentralised modification. It also enables integration into local cycles, as the technology can be easily adapted to needs and integrated into infrastructures. In order to ensure this, the basic rule with regard to design is that the application should be structured into a generic core with open interfaces. This covers cross-platform basic functions and enables adaptation to different requirements by facilitating the development of connectable applications.

While open-source is a widespread topic in the realm of software and enriches large parts of software development, opensource hardware is still in its infancy. Worse: Anyone who remembers the 50s and 60s knows that the circuit diagram was often an integral part of purchased devices. Nowadays, technical connections disappear more and more in sealed casings that are supposed to give as few reasons as possible for opening them - the technical documentation of the devices only pro- 


\section{"Makerspaces are places for raising and spreading new ideas, for self-empowerment and participation in open-source."}

It is therefore necessary to further develop dedicated versioning systems.

Another challenge is the question of when hardware is really documented for re-use. This is because reconstructing physical objects requires very different resources, such as technical drawings, parts lists or assembly plans. The DIN SPEC 3105 (Meyer 2020) and the OPEN! project provide initial answers, by developing frameworks and evaluation criteria.

\section{Makerspaces}

When seen through the magnifying glass of the pandemic, the decades-long failings in adapting the education system to the needs of the postmodern age are particularly evident. Teaching digital, technical and technological skills is still in its infancy. This, along with the division of labour, has also resulted in an intellectual decoupling from the technical infrastructure, which we as consumers are now blindly at the mercy of (Simondon 2012). This creates numerous problems, especially when it comes to resource-saving use. Technical-technological competences are an essential basis for leading a self-determined and resource-saving life. Fostering these and not putting undue strain on educational institutions requires open spaces where learners and teachers can engage with technology in a self-determined way, to develop their own approaches. Such access is provided by numerous extracurricular places of learning throughout Germany, such as makerspaces.

The character of a makerspace emerges when comparing it to a vocational training workshop. There, the focus is on concrete job profiles with a productive character. There are teachers who imbue trainees with knowledge or make them fit for a certain branch of work or a specific job profile. The goal is therefore a certain level of qualification. This stands in contrast to makerspaces. Such experts may also be on hand there, but they are not the centre of attention. Rather, it is about the mutual empowerment of equals. This does not have the primary aim of producing a qualification certificate, but is about the practical hands-on knowledge itself. Makerspaces bring together people who are interested in learning by doing, in passing on their experiences to others and in becoming a social community. This self-determined learning enables very individual access to technical objects and in this way also promotes the responsible use of technology in everyday life.

\section{Interfaces for local learning and economic development}

In addition to social and technical engagement, makerspaces are also learning spaces in which the sharing of knowledge, which is the fundamental practice behind open-source, becomes tangible. As hubs of regional learning networks, they can bring together numerous knowledge resources and promote exchange. In this way, innovations from civil society and extra-institutional contexts are transported into formal institu- 
tions and an open learning culture is established that focuses on collaboration and instils a culture of knowledge sharing.

Makerspaces also play a prominent role with regard to local economic spaces, such as circular systems. They enable customised one-offs or spare parts that are no longer available to be produced (rapid manufacturing), as well as the further development and repair of existing technologies. Typical equipment in addition to common hand tools, typical equipment includes a 3D printer, laser cutter and other CNC machines to process different materials and workpieces. True to the motto: make almost everything (Bergner 2017).

\section{Visions for structural change}

Embedded in local contexts, makerspaces are places for raising and spreading new ideas, for self-empowerment and participation in open-source. Emancipation from outmoded structures and the search for new ways of doing business are particularly important in rural areas. The context of makerspaces gives rise to a resilient civil society that is largely independent of global structures and taps into its own, local resources (Lange et al. 2016). Open-source hardware and software, solution-oriented action, infrastructures of mid-range technologies that improve independent experimentation and locally situated economies enable promising visions for a resource-efficient life.

\section{References}

Bergner, A. (2017): Make-Design-Innovate. Das Potential des Maker-Movements für Innovation, Kreativwirtschaft und Unternehmen. Coburg, Hochschule für angewandte Wissenschaften Coburg.

Austic, G./Stirling, J./Molloy, J. (2020): Open Hardware Distribution \& Documentation Working Group: Introduction to Documentation and Quality Assurance Frameworks. https://journalopenhw.medium.com/ open-hardware-distribution-documentation-working-group-introductionto-documentation-and-5543bc978eec

Lange, B./Domann, V./Häfele, V. (2016): Wertschöpfung in offenen Werkstätten. Eine empirische Befragung offener Werkstätten in Deutschland. Berlin, IÖW.

Meyer, C. (2020): DIN SPEC 3105: Normungsvorschlag für Open-SourceHardware. www.heise.de/news/DIN-SPEC-3105-Normungsvorschlag-fuerOpen-Source-Hardware-4868528.html

Pearce, J. M. (2017): Emerging Business Models for Open Source Hardware. In: Journal of Open Hardware 1/1: 1-14.

Simondon, G. (2012): Die Existenzweise technischer Objekte. Zürich, diaphanes.

AUTHOR + CONTACT

Maximilian Voigt works as a project manager for educational projects and the topic of open hardware at the Open Knowledge Foundation Germany and is a board member of the Association of Makerspaces in Germany.

Open Knowledge Foundation Deutschland e. V., Singerstr. 109, 10179 Berlin. E-mail: maximilian.voigt@okf.de

\section{DIE ZUKUNFT DES WIRTSCHAFTENS BEGINNT JETZT!}

Die Zeitschrift Ökologisches Wirtschaften schließt die Lücke zwischen Theorie und Praxis einer nachhaltigen Gestaltung der Wirtschaft.

\section{GÜNSTIGES PROBEABO}

\section{Zwei Ausgaben für nur 19,- Euro statt 37,50 Euro (inkl. Versand)}

Bestellung an: abo@oekom.de

Herausgegeben von Institut und Vereinigung für

ökologische Wirtschaftsforschung (IÖW und VÖW).

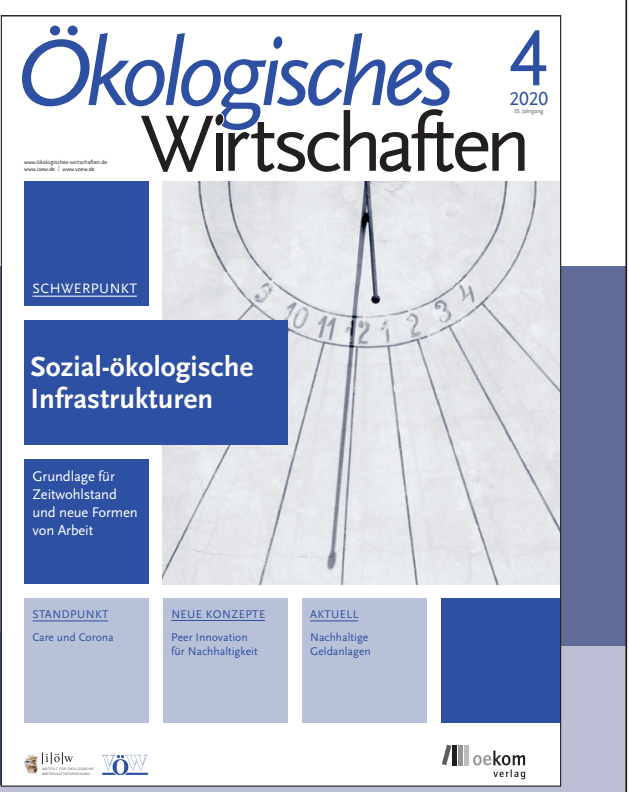

Leseproben, Informationen zur Zeitschrift und Abobedingungen: www.oekologisches-wirtschaften.de 